\title{
Movements and use of space by Mangrove Cuckoos (Coccyzus minor) in Florida, USA
}

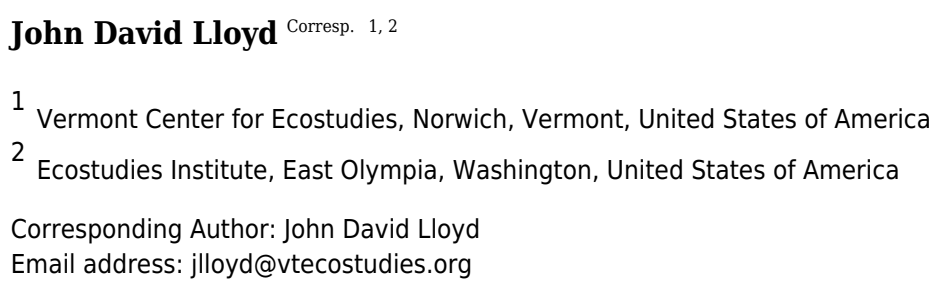

I used radio-telemetry to track the movements of Mangrove Cuckoos (Coccyzus minor) captured in southwest Florida. Relatively little is known about the natural history of Mangrove Cuckoos, and my goal was to provide an initial description of how individuals use space, with a focus on the size and placement of home ranges. I captured and affixed VHF radio-transmitters to 32 individuals between 2012 and 2015, and obtained a sufficient number of relocations from 16 of them to estimate home-range boundaries and describe patterns of movement. Home-range area varied widely among individuals, but in general, was roughly four times larger than expected based on the body size of Mangrove Cuckoos. The median core area (50\% isopleth) of a home range was 42 ha (range: 9 - 91 ha), and the median overall home range (90\% isopleth) was 128 ha (range: 28 - 319 ha). The median distance between estimated locations recorded on subsequent days was $298 \mathrm{~m}$ $(95 \% \mathrm{Cl}=187 \mathrm{~m}-409 \mathrm{~m})$, but variation within and among individuals was substantial, and it was not uncommon to relocate individuals $>1 \mathrm{~km}$ from their location on the previous day. Site fidelity by individual birds was low; although Mangrove Cuckoos were present year-round within the study area, I did not observe any individuals that remained on a single home range throughout the year. Although individual birds showed no evidence of avoiding anthropogenic edges, they did not incorporate developed areas into their daily movements and home ranges consisted almost entirely of mangrove forest. The persistence of the species in the study area depended on a network of conserved lands mostly public, but some privately conserved land as well - because large patches of mangrove forest did not occur on tracts left unprotected from development. 
1 Movements and use of space by Mangrove Cuckoos (Coccyzus minor) in Florida, USA

2

3 John David Lloyd ${ }^{1,2}$

$4 \quad{ }^{1}$ Ecostudies Institute, P.O. Box 735, East Olympia, WA 98540

$5 \quad{ }^{2}$ Current address: Vermont Center for Ecostudies, PO Box 420, Norwich, VT 05055

6

7 Corresponding Author:

8 John Lloyd

9 Email address: jlloyd@vtecostudies.org

10 
11 Abstract

12 I used radio-telemetry to track the movements of Mangrove Cuckoos (Coccyzus minor) captured

13 in southwest Florida. Relatively little is known about the natural history of Mangrove Cuckoos,

14 and my goal was to provide an initial description of how individuals use space, with a focus on

15 the size and placement of home ranges. I captured and affixed VHF radio-transmitters to 32

16 individuals between 2012 and 2015, and obtained a sufficient number of relocations from 16 of

17 them to estimate home-range boundaries and describe patterns of movement. Home-range area

18 varied widely among individuals, but in general, was roughly four times larger than expected

19 based on the body size of Mangrove Cuckoos. The median core area (50\% isopleth) of a home

20 range was 42 ha (range: 9 - 91 ha), and the median overall home range (90\% isopleth) was 128

21 ha (range: 28 - 319 ha). The median distance between estimated locations recorded on

22 subsequent days was $298 \mathrm{~m}(95 \% \mathrm{CI}=187 \mathrm{~m}-409 \mathrm{~m})$, but variation within and among

23 individuals was substantial, and it was common to relocate individuals $>1 \mathrm{~km}$ from their location

24 on the previous day. Site fidelity by individual birds was low; although Mangrove Cuckoos were

25 present year-round within the study area, I did not observe any individuals that remained on a

26 single home range throughout the year. Although individual birds showed no evidence of

27 avoiding anthropogenic edges, they did not incorporate developed areas into their daily

28 movements and home ranges consisted almost entirely of mangrove forest. The persistence of the

29 species in the study area depended on a network of conserved lands - mostly public, but some

30 privately conserved land as well - because large patches of mangrove forest did not occur on

31 tracts left unprotected from development.

32

33 Introduction 
34 Understanding how animals use space and move through the environment around them can

35 provide important insights into their ecology and conservation (Kramer and Chapman, 1999;

36 Wiens, 2008; Holland et al., 2009). Information concerning an animal's home range - that is, the

37 area in which an organism carries out the day-to-day activities of life (Burt, 1943) - can be

38 particularly useful, helping to identify habitat requirements, predict sensitivity to habitat loss and

39 fragmentation, and delineate areas important for conservation. I documented patterns of

40 movement and described characteristics of Mangrove Cuckoo (Coccyzus minor Gmelin) home

41 ranges in southwest Florida, USA. Mangrove Cuckoos are widespread and relatively common in

42 a variety of forested environments throughout the Caribbean and Middle America (Lloyd, 2013).

43 In Florida, the northern limit of their geographic distribution, they are uncommon and apparently

44 restricted largely to mangrove forests (Lloyd, 2013; Lloyd and Slater, 2014). Although the

45 species is of Least Concern globally (BirdLife International, 2012), Mangrove Cuckoos in the

46 United States are a high priority for conservation action (Partners in Flight Science Committee,

47 2012) and are considered at risk of becoming threatened (U.S. Fish and Wildlife Service, 2008),

48 with some evidence of recent declines in parts of Florida (Lloyd and Doyle, 2011). An important

49 obstacle to planning conservation action, however, is the lack of information on the natural

50 history of Mangrove Cuckoos; they remain one of North America's least-studied birds (Hughes,

51 2010).

52

53 My goal was to enhance understanding of the natural history of Mangrove Cuckoos by providing

54 an initial description of space use; as with other facets of the species' ecology, basic patterns of

55 space use are undocumented. To address this information gap, I sought to quantify patterns of

56 movement among individuals, estimate the amount of area required to support a Mangrove 
57 Cuckoo home range, and describe qualitatively the land-cover types in which Mangrove

58 Cuckoos will establish a home range. Information on area requirements and habitat use may help 59 inform future conservation efforts. I did not document what sorts of activities birds engaged in 60 during the period of time that I followed them (e.g., whether they were nesting), so here I adopt a 61 simple empirical approach of allowing the movement of individual birds to define an area of 62 concentrated use that I refer to as a home range (sensu Burt, 1943).

63

64 Methods

65 Study area

66 I captured Mangrove Cuckoos from 2012-2015 at J.N. "Ding” Darling National Wildlife Refuge $67\left(26.44^{\circ} \mathrm{N},-82.11^{\circ} \mathrm{W}\right)($ hereafter, "Ding Darling NWR") on the barrier island of Sanibel and at San 68 Carlos Bay - Bunche Beach Preserve $\left(26.48^{\circ} \mathrm{N},-81.97^{\circ} \mathrm{W}\right)$ on the nearby mainland coast in Fort 69 Myers. The study area, however, encompassed all of the locations where I relocated marked 70 birds, ranging from near Port Charlotte to Fort Myers Beach (Fig. 1). Mangrove forests fringe 71 protected coastlines in this area and are dominated by red (Rhizophora mangle L.) and black 72 (Avicennia germinans L.) mangrove, with lesser numbers of white mangrove (Laguncularia 73 racemosa C. F. Gaertn.). Canopy height in general was less than $7 \mathrm{~m}$. The inland edge of most 74 mangrove forest in the region abuts developed land, where nearly all uplands have been cleared 75 of native vegetation for commercial and residential development. Where uplands have been 76 protected - almost exclusively on Sanibel - adjacent forest types include hammock forests 77 dominated by southern live oak (Quercus virginiana Mill.) and a variety of tropical hardwoods, 78 savannas of cabbage palm (Sabal palmetto Lodd. ex Schult.f.), and pure stands of buttonwood 79 (Conocarpus erectus L.) (Cooley, 1955). 
80

81 The climate of the area is tropical (Duever et al., 1994). Air temperatures remain relatively warm

82 throughout the year, with mean monthly temperature ranging from $17.8^{\circ} \mathrm{C}$ in January to $28.1^{\circ} \mathrm{C}$

83 in August (based on climate data from 1892-2012 collected in Fort Myers; available online at

84 http://www.sercc.com). Frosts are uncommon, especially in mangroves. Most (65\%) of the mean

85 annual precipitation $(136 \mathrm{~cm})$ falls during convective storms in the pronounced wet season (June

86 to September). Weather between October and May is drier and cooler, and precipitation that falls

87 during the dry season is generally driven by the passage of cold fronts. Tropical cyclones strike

88 occasionally, although none affected the area during this study.

89

90 Field methods

91 I located birds by broadcasting a recorded vocalization of Mangrove Cuckoo, to which

92 individuals respond readily when present (Frieze et al., 2012), in areas of suitable habitat

93 (mangrove forest) that could be accessed by boat, on foot, or by motor vehicle. In 2012, searches

94 were conducted between March and August; in 2013, between February and August; and then

95 continually from February 2014 - June 2015. The start and end dates of searches in 2013 and

962014 were dependent on the availability of personnel to assist with searches.

97

98 The vocalization used during playback (Hardy, 1998) was downloaded from the website of the

99 Florida Museum (http://www.flmnh.ufl.edu/birds/florida-bird-sounds/) and consisted of the

100 typical guttural series of "cah" notes, lasting for 8 seconds. Broadcasts were made using a small

101 handheld speaker and an MP3 player, with the volume set to a level at which the sound could be

102 distinguished by a human observer at a distance of approximately $100 \mathrm{~m}$. I listened quietly after 
103 each playback, repeating the broadcast up to 3 times if no individuals were detected.

104

105 Once a bird had been located, it was lured into a mist net via playback of recorded vocalizations.

106 Upon capture, each bird was marked with an aluminum US Fish and Wildlife Service leg-band

107 and a unique combination of three colored plastic leg-bands. A VHF radio-transmitter (American

108 Wildlife Enterprises, Monticello, Florida and ATS, Isanti, Minnesota) was attached using flat,

109 2.5-mm-wide elastic fabric to create leg loops as per Rappole and Tipton (1991). The transmitter

110 and harness collectively weighed $1.8 \mathrm{~g}$, or approximately $2.9 \%$ of the average mass of Mangrove

111 Cuckoos captured in this study (mean body mass $=62.5 \mathrm{~g} ; \mathrm{n}=46$ ). Protocols and materials used

112 in capture, handling, and marking were designed in accordance with guidelines presented by Fair

113 et al. (2010). This research was conducted with the permission of the US Fish and Wildlife

114 Service (Special Use Permit No.13036), the USGS Bird Banding Laboratory (Bird-Banding

115 Permit No. 23726 issued to JDL), and the State of Florida (Scientific Collecting Permit No.

116 LSSC-11-00048A).

117

118 Birds were released as soon as possible after capture (average time between capture in the mist

119 net and release of a radio-marked bird was 27 minutes). I attempted to relocate radio-marked

120 birds every 1-3 days using a handheld antenna, although this frequency of relocation was

121 possible only for birds that remained in the core of the study area. Individuals that moved long

122 distances or occupied remote areas that could only be searched by plane were relocated less

123 frequently, generally every 2-3 weeks.

124

125 When an individual could not be located after multiple ground-based searches, a fixed-wing 
126 airplane was used to search a wider area. Aerial searches typically focused on an area within 60

$127 \mathrm{~km}$ of the last known location. Location of individuals detected during aerial searches was

128 estimated from the plane's Global Positioning System (GPS) after the signal had been localized

129 using directional antennae and close circling by the pilot.

130

131 Radio-marked individuals were tracked throughout each field season (see above for dates) or

132 until multiple aerial searches failed to detect them. The nominal battery life of the transmitters

133 ranged from 3-6 months depending on the unit, but in general I could not distinguish battery

134 failure from permanent emigration out of the search area.

135

136 Estimating telemetry error

137 To test the telemetry system, a naïve observer used biangulation to identify the location of a

138 radio transmitter that had been placed in a known location by a second observer. The transmitters

139 were placed on horizontal limbs of mangrove trees in locations that were representative of

140 perches used by Mangrove Cuckoos. I conducted 16 trials; 6 in February of 2012 and 10 in July

141 of 2012. The same observer was used in every trial. In 14 trials, the observer was able to obtain

142 bearings from land, but in the other 2 trials the location of the hidden transmitter required the

143 observer to take bearings from a kayak. I calculated error as the distance between the actual

144 location of the transmitter as determined by a handheld GPS unit and the location estimated from

145 biangulation.

146

147 Efficacy of aerial searches

148 I also conducted a test of the efficacy of aerial searches from a fixed-wing airplane. On a single 
149 day, a pilot flew at different altitudes above a transmitter positioned at a known location in a

150 mangrove forest. The plane passed directly over the transmitter at $305 \mathrm{~m}, 457 \mathrm{~m}$, and $610 \mathrm{~m}$, and

151 then flew passes at different distances to either side of the transmitter, again repeating passes at

152 each of the 3 altitudes.

153

154 Statistical analysis of movements and space use

155 I estimated the location of marked birds by triangulating the signal based on compass bearings

156 and GPS locations obtained in the field. I described home ranges of radio-marked Mangrove

157 Cuckoos using the Brownian bridges movement model of Horne et al. (2007), as implemented in

158 the R package adehabitatHR (Calenge, 2006). This model requires time-stamped locations and

159 two smoothing parameters, one related to the speed at which the organism moves through space

160 (the Brownian motion variance parameter) and one that describes the imprecision of estimated

161 locations. I calculated the Brownian motion variance parameter using the likelihood method

162 proposed by Horne et al. (2007) and implemented by the liker function in the adehabitatHR

163 package. I used the results of the ground-based telemetry-error tests to calculate the standard

164 deviation of the mean location error, the second smoothing parameter (I have only qualitative

165 information about error during aerial searches). In estimating the boundaries of home ranges, I

166 censored from analysis any individuals with $\leq 20$ relocations due to concerns about small-sample

167 bias. Based on the recommendation of Borger et al. (2006), I defined the total home range as the

$16890 \%$ isopleth of the utilization distribution, and the core home range as the $50 \%$ isopleth.

169 Location data used to estimate the home-range boundaries are available in Lloyd (2017).

170

171 Home-range boundaries for Mangrove Cuckoos in this area tended to include large areas of open 
172 water, which I did not include in calculations of home-range area. The amount of open water

173 within each home range was calculated using a shapefile of the Florida coastline (version 2004)

174 published by the State of Florida (available at http://www.fgdl.org) and then subtracted from the

175 area within the $90 \%$ and $50 \%$ isopleths. Home-range size calculations were performed within

176 QGIS version 2.16.3 (QGIS Development Team 2016); all other analyses were conducted in R

177 3.2.4 (R Core Team 2016).

178

179 I used the shapefile (version April 2015) published by the Fish and Wildlife Research Institute 180 (FWRI) at the Florida Fish and Wildlife Conservation Commission to determine the distribution 181 of mangrove vegetation within the study area (available at http://www.fgdl.org). I determined 182 protected area boundaries using version 1.4 of the U.S. Geological Survey's Protected Areas 183 Database of the United States (available at: http://gapanalysis.usgs.gov/padus/).

185 Results

186 Telemetry error

187 The estimated mean telemetry error associated with ground-based searches was $35.1 \mathrm{~m}(\mathrm{SD}=$ $18828.6 \mathrm{~m}$; range $=5.7 \mathrm{~m}-105.3 \mathrm{~m})$.

189 Efficacy of aerial searches

190 Flying directly over the transmitter at $305 \mathrm{~m}$ altitude, the signal was detected $1.1 \mathrm{~km}$ before the 191 plane passed over the transmitter and was lost when the plane had passed $1.0 \mathrm{~km}$ beyond the 192 location of the signal. At this altitude, the signal was not detected at the 1 or $2 \mathrm{~km}$ offset passes. 193 At $457 \mathrm{~m}$ altitude, the signal was detected $1.8 \mathrm{~km}$ before the plane passed over the transmitter 194 and was lost when the plane had passed $800 \mathrm{~m}$ beyond the transmitter. The signal was located on 
195 offset passes as far as $2 \mathrm{~km}$ adjacent to the path directly over the signal. At $610 \mathrm{~m}$ altitude, the 196 signal was detected $1.7 \mathrm{~km}$ before the plane passed over the transmitter and was lost when the 197 plane had passed $900 \mathrm{~m}$ beyond the transmitter. The signal was located on offset passes as far as $1982 \mathrm{~km}$ adjacent to the path directly over the signal. These results suggest that, at altitudes typical 199 of those maintained during aerial searches $(>400 \mathrm{~m})$, the detection radius for a transmitter on the 200 ground was approximately 1-2 km. Patches of mangrove forests in the study area were always $<4$ $201 \mathrm{~km}$ in width, and most were $<1 \mathrm{~km}$ wide (e.g., Fig. 1).

202

203 Movements and space use by Mangrove Cuckoos

204 I captured 46 individuals between 2012 and 2015. I did not recapture or resight any marked 205 individuals outside of the year in which they were initially captured (except for one individual 206 captured in late 2014 and tracked into early 2015). I captured individuals in every month except

207 February, but most captures $(\mathrm{n}=27)$ occurred between March and May (Fig. 2). I radio-marked 20832 of these individuals, and obtained an adequate number of relocations for 16 of these to 209 describe a home range. Of the 16 individuals censored from the home-range analysis due to 210 small sample size, six were tracked for relatively long periods of time $(127,123,114,111,103$, 211 and 45 days, respectively) but occupied areas where transmitter signals could only be detected by

212 plane and thus were relocated infrequently. The other 10 were transient (or carried transmitters

213 that failed prematurely); most of these individuals were known to be present in the study area for $214<2$ weeks (average number of days known present $=13$; range $=2-31$ days).

216 In general, individuals moved widely from day to day. The median distance between estimated 217 locations recorded on subsequent days was $298 \mathrm{~m}(95 \% \mathrm{CI}=187 \mathrm{~m}-409 \mathrm{~m})$, but variation 
218 within and among individuals was substantial, and individuals were occasionally found $>1 \mathrm{~km}$

219 from their location on the previous day (Fig. 3). Notable movements included a flight taken by

220 individual 150.919 from its home range in Ding Darling NWR to the San Carlos Bay - Bunche

221 Beach Preserve and back again, a round-trip distance of roughly $35 \mathrm{~km}$. This individual was

222 located on its home range at 07:01 on 18 July 2012, but by the following morning at 09:59 it had

223 moved to a location in San Carlos Bay - Bunche Beach Preserve on the mainland, a straight-line

224 distance of $16.8 \mathrm{~km}$. It was not located on $20 \mathrm{July}$. On 21 July at 08:06 it had returned to nearly

225 the same location where it had been found on 18 July. This individual then remained on its home

226 range on Sanibel until at least 21 November 2012, and during that time made no other similar

227 movements. Although the purpose of that single long-distance movement is unknown, it was

228 evidently not part of a dispersal event to a new home range.

229

230 Home-range area was generally large but variable among individuals (Table 1). Home-range area 231 did not covary with the length of the period during which I tracked each individual (total home 232 range: $\mathrm{r}=0.30,95 \% \mathrm{CI}=-0.23-0.69$; core area: $\mathrm{r}=0.26,95 \% \mathrm{CI}=-0.25-0.66$ ) or with the 233 number of times an individual was relocated (total home range: $\mathrm{r}=0.29,95 \% \mathrm{CI}=-0.24-0.69$;

234 core area: $\mathrm{r}=0.16,95 \% \mathrm{CI}=-0.35-0.59)$. Of the 16 individuals for which I estimated a home 235 range, 11 were last detected within its boundaries. The other 5 individuals $(150.613,150.757$, $236149.881,148.872$, and 149.281) were later located 1-3 times at locations far removed from the

237 home-range boundaries (c.a. $12-55 \mathrm{~km}$ from the last estimated location within the home range).

238 None of these five individuals ever returned, and thus presumably had abandoned the home 239 range and were in the process of dispersing when last located. Timing of departure, for these five 240 individuals, ranged from early May (149.281) to late July (150.757). The trigger for these 
241 dispersal events is unknown.

242

243 The same areas were frequently used as home ranges by different birds in different years, but

244 concurrent use of overlapping home ranges or core-use areas was observed in only one instance.

245 Three individuals - 150.775, 150.829, and 150.819- occupied broadly overlapping (i.e., $>50 \%$

246 overlap) home ranges and core-use areas at the same time in San Carlos Bay - Bunche Beach

247 Preserve. I did not observe interactions among these individuals, so it is unclear whether they

248 were part of a social unit. However, all three individuals were located in close proximity to one

249 another on numerous occasions throughout the period during which they were tracked.

250

251 Nearly 75\% of estimated locations of marked Mangrove Cuckoos fell within areas classified as 252 mangroves (756 locations from a total of 1,015 locations gathered during the course of the study) 253 and $94 \%$ of all estimated locations fell within $100 \mathrm{~m}$ of mangrove vegetation as defined by the 254 FWRI shapefile. Mangrove vegetation in the study area is limited primarily to protected areas, 255 and as consequence nearly every (99\%; $n=1002$ locations) estimated location of a Mangrove 256 Cuckoo occurred within a protected area. In addition to the two main capture areas, Ding Darling

257 NWR ( $\mathrm{n}=590$ locations) and San Carlos Bay - Bunche Beach Preserve ( $\mathrm{n}=156$ locations), 258 other protected areas used by Mangrove Cuckoos included conservation lands managed by 259 Sanibel-Captiva Conservation Foundation $(\mathrm{n}=68)$, Charlotte Harbor Preserve State Park $(\mathrm{n}=$ 260 35), Estero Bay Preserve State Park $(n=22)$, and Matlacha Pass NWR $(n=6)$.

262 Discussion

263 Home-range size of Mangrove Cuckoos captured on public land in southwest Florida was 
264 substantially larger than predicted based on the allometry of space use by animals (Schoener, 265 1968; Mace and Harvey, 1983). Indeed, with a median home-range size of 132 ha, space use by

266 Mangrove Cuckoos is similar to that of a small raptor such as Red-shouldered Hawk (Buteo

267 lineatus Gmelin; average home-range size $=135 \mathrm{ha})($ Peery, 2000), even though its body size is

268 roughly $15 \%$ that of the Red-shouldered Hawk. Little information exists on home-range size of

269 other New World cuckoos. Yellow-billed Cuckoos (Coccyzus americanus Linnaeus) in riparian

270 forests in Arizona occupied home ranges that averaged 39 ha (95\% kernel-density estimate) to 51

271 ha (minimum convex polygon) during the breeding season (Halterman, 2009), and a single

272 Banded Ground-cuckoo (Neomorphus radiolosus Sclater \& Salvin) - a distantly related and far

273 larger species - occupied a home-range in Ecuador estimated to consist of 42.2 ha (MCP) to 49.9

274 ha (95\% kernel-density estimate) (Karubian and Carrasco, 2008). Likewise, information on space

275 use by other birds of mangrove forest is scarce; Yellow-billed Cotinga (Carpodectes antoniae

276 Ridgway), a substantially larger (85-90g) inhabitant of mangrove forests in Costa Rica and

277 Panama, used somewhat smaller home ranges (31.2 ha and 107.2 ha, respectively, during the

278 breeding and non-breeding seasons) and core-use areas (6.6 ha and 24.3 ha, respectively)

279 (Leavelle et al., 2015).

280

281 The Mangrove Cuckoos tracked in this study showed no inter-annual site fidelity. I documented 282 several instances in which the same patch of mangrove was occupied by a different individual in 283 each year of the study. Indeed, during the course of the study, I never recaptured - and only once 284 resighted - an individual marked in a previous year; this suggests a nomadic lifestyle, as has 285 been argued for other Coccyzus cuckoos. Although Mangrove Cuckoos were present in the study 286 area year-round, I found no evidence that any individual remained resident in the same area 
287 throughout the year.

288

289 Why might Mangrove Cuckoos use disproportionately large home ranges and show an apparent 290 tendency to wander widely? Perhaps it is worth considering use of space within the context of

291 the unusual suite of life-history traits that seem to characterize Mangrove Cuckoo and two of its

292 more well-studied congeners: Yellow-billed Cuckoo and Black-billed Cuckoo $(C$.

293 erythropthalmus Wilson). Based on what is known of these species, in addition to occupying

294 large home ranges, they exhibit remarkably rapid developmental rates, are facultative

295 intraspecific brood parasites, have low inter-annual fidelity to breeding sites and highly variable

296 investment in reproduction, and seem to engage in inexplicable, long-distance movements before

297 and after breeding (Fleischer et al., 1985; Hughes, 2001, 2010, 2015; Dearborn et al., 2009;

298 Sechrist et al., 2012). These traits have been explained as an adaptation to a lifestyle centered

299 around exploiting super-abundant but patchy, ephemeral, and unpredictable food resources

300 (Hamilton and Hamilton, 1965; Nolan and Thompson, 1975; Sealy, 1985; Barber et al., 2008).

301 Evidence for this hypothesis is largely circumstantial, however (e.g., see Hughes, 1997 for a

302 critique), and it is not clear if the food resources used by Mangrove Cuckoos are as variable as

303 those considered critical for Yellow-billed and Black-billed cuckoos. The diet of Mangrove

304 Cuckoos is known poorly but seems to include a predilection for large invertebrates and small

305 vertebrates (Lloyd, 2013) and thus the large home ranges that I observed may have reflected a

306 diet focused on relatively large prey items - a characteristic associated with large home ranges

307 (Schoener, 1968) - rather than a diet based on highly variable prey populations. However, as

308 with other Coccyzus cuckoos, rigorous tests of these ideas await longer-term studies of breeding

309 biology and natural history. For Mangrove Cuckoos, this would include research that links 
310 movement patterns to breeding behavior; tracks individuals across longer temporal and larger 311 spatial scales; and rigorously quantifies diets of adults, juveniles, and nestlings. Finally, I note

312 that I only sampled individuals living in relatively small patches of forest surrounded by urban

313 development. It is possible that birds living in areas with more extensive mangrove forest, for

314 example in Everglades National Park, may exhibit different movement patterns. Comparative

315 research in other areas would help verify the findings presented here.

316

317 Although many puzzles remain concerning the natural history of Mangrove Cuckoos, the

318 conditions needed to conserve the species are clear: a network of intact, protected patches of

319 mangrove forest. In south Florida, this network consists almost entirely of publically owned land.

320 Stands of mangrove forest large enough to support Mangrove Cuckoos do not occur on private

321 land. Some important protected areas - Ding Darling NWR, for example - were established to

322 conserve habitat for wildlife, but other important protected areas, like Charlotte Harbor Preserve

323 State Park, were established largely for shoreline protection and water-quality improvement. No

324 matter what the rationale for investing in mangrove protection, the continued persistence of

325 Mangrove Cuckoos in Florida depends on the preservation of remaining mangrove forests.

326

327 Acknowledgments

328 I gratefully acknowledge the assistance of Rachel Frieze and the staff of the J.N. "Ding" Darling

329 National Wildlife Refuge, especially J. Palmer, P. Tritaik, T. Wertz and J. Conrad. I also

330 acknowledge the helpful support and assistance of S. Mullin, J. and A. Kirk, B. Fischer, A.

331 Parker, K. Ramos, M. Gallagher, and M. McLaughlin. J. Hill and C. Rimmer provided valuable

332 comments on an earlier version of this manuscript. 
334

335

336

337

338

339

340

341

342

343

344

345

346

347

348

349

350

351

352

353

354

355

356

357

358

359

360

361

362

363

364

365

366

367

368

369

370

371

372

373

374

375

376

377

References

Barber NA, Marquis RJ, Tori WP. 2008. Invasive prey impacts the abundance and distribution of native predators. Ecology 89:2678-2683.

BirdLife International. 2012. Coccyzus minor. The IUCN Red List of Threatened Species 2012: e.T22684337A40060825. [Online.] Available at http://dx.doi.org/10.2305/IUCN.UK.20121.RLTS.T22684337A40060825.en.

Borger L, Franconi N, De Michele G, Gantz A, Meschi F, Manica A, Lovari S, Coulson T. 2006. Effects of sampling regime on the mean and variance of home range size estimates. Journal of Animal Ecology 75:1393-1405.

Burt WH. 1943. Territoriality and home range concepts as applied to mammals. Journal of Mammalogy 24:346-352.

Calenge C. 2006. The package "adehabitat" for the R software: A tool for the analysis of space and habitat use by animals. Ecological Modelling 197:516-519.

Cooley GR. 1955. The vegetation of Sanibel Island, Lee County, Florida. Rhodora 57:269-289.

Dearborn DC, MacDade LS, Robinson S, Dowling Fink AD, Fink ML. 2009. Offspring

development mode and the evolution of brood parasitism. Behavioral Ecology 20:517-525.

Duever MJ, Meeder JF, Meeder LC, McCollom JM. 1994. The climate of south Florida and its role in shaping the Everglades ecosystem. In: Davis SM, Ogden JC, eds. Everglades: the ecosystem and its restoration. Boca Raton: St Lucie Press, 225-248.

Fair J, Paul E, Jones J. 2010. Guidelines to the use of wild birds in research. Washington, DC: Ornithological Council.

Fleischer RC, Murphy MT, Hunt LF. 1985. Clutch size increase and intraspecific brood parasitism in the Yellow-billed Cuckoo. Wilson Bulletin 97:125-127.

Frieze RD, Mullin SM, Lloyd JD. 2012. Responsiveness of mangrove cuckoo (Coccyzus minor) during call-playback surveys in southern Florida. Southeastern Naturalist 11:447-454.

Halterman MM. 2009. Sexual dimorphism, detection probability, home range, and parental care in the Yellow-billed Cuckoo. Ph.D. Dissertation, University of Nevada.

Hamilton WJ III, Hamilton ME. 1965. Breeding characteristics of Yellow-billed Cuckoos in Arizona. Proceedings of the California Academy of Sciences 32:405-432.

Hardy JW. 1998. Sounds of Florida’s Birds, 1998. Available at: 
378 http://www.flmnh.ufl.edu/birds/florida-bird-sounds/.

379

380

381

382

383

384

385

386

387

388

389

390

391

392

393

394

395

396

397

398

399

400

401

402

403

404

405

406

407

408

409

410

411

412

413

414

415

416

417

418

419

420

421

422

423

Holland RA, Wikelski M, Kümmeth F, Bosque C. 2009. The secret life of oilbirds: New insights into the movement ecology of a unique avian frugivore. PLOS ONE 4:e8264.

Horne JS, Garton EO, Krone SM, Lewis JS. 2007. Analyzing animal movements using Brownian bridges. Ecology 88:2354-2363.

Hughes JM. 1997. Taxonomic significance of host-egg mimicry by facultative brood parasites of the avian genus Coccyzus (Cuculidae). Canadian Journal of Zoology 75:1380-1386.

Hughes JM. 2001. Black-billed Cuckoo (Coccyzus erythropthalmus). In: Rodewald, PG, ed. The Birds of North America Online. Ithaca: Cornell Lab of Ornithology. Available at:

https://birdsna.org/Species-Account/bna/bkbcuc. DOI: 10.2173/bna.587

Hughes JM. 2012. Mangrove Cuckoo (Coccyzus minor). In: Rodewald, PG, ed. The Birds of North America Online. Ithaca: Cornell Lab of Ornithology. Available at:

https://birdsna.org/Species-Account/bna/mancuc. DOI: 10.2173/bna.299

Hughes, JM. 2015. Yellow-billed Cuckoo (Coccyzus americanus). In: Rodewald, PG, ed. The Birds of North America Online. Ithaca: Cornell Lab of Ornithology. Available at:

https://birdsna.org/Species-Account/bna/yebcuc. DOI: 10.2173/bna.418

Karubian J, Carrasco L. 2008. Home range and habitat preferences of the Banded Groundcuckoo (Neomorphus radiolosus). Wilson Journal of Ornithology 120:205-209.

Kramer DL, Chapman MR. 1999. Implications of fish home range size and relocation for marine reserve function. Environmental Biology of Fishes 55:65-79.

Leavelle KM, Powell LL, Powell GVN, Forsyth A. 2015. A radio-telemetry study of home range and habitat use of the endangered Yellow-billed Cotinga (Carpodectes antoniae) in Costa Rica. Wilson Journal of Ornithology 127:302-309.

Lloyd, JD. 2013. Mangrove Cuckoo (Coccyzus minor). In: Schulenberg TS, ed. Neotropical Birds Online. Ithaca: Cornell Lab of Ornithology. Available at:

http://neotropical.birds.cornell.edu/portal/species/overview?p p spp=202776.

Lloyd JD, Doyle T. 2011. Abundance and population trends of mangrove landbirds in southwest Florida. Journal of Field Ornithology 82:132-139.

Lloyd JD, Slater GL. 2014. Abundance and distribution of mangrove landbirds in Florida. North American Fauna 80:1-45.

Lloyd J. 2017. Mangrove Cuckoo Radio-telemetry Study. Available at: https://doi.org/10.6084/m9.figshare.4628017.v1. 
424 Mace GM, Harvey PH. 1983. Energetic constraints on home-range size. American Naturalist 425 121:120-132.

426

427

428

429

430

431

432

433

434

435

436

437

438

439

440

441

442

443

444

445

446

447

448

449

450

451

452

453

454

455

456

457
Nolan V Jr, Thompson CF. 1975. The occurrence and significance of anomalous reproductive activities in two North American non-parasitic cuckoos Coccyzus spp. Ibis 117:496-503.

Partners in Flight Science Committee. 2012. Species assessment database, version 2012. Available at: http://rmbo.org/pifassessment.

Peery MZ. 2000. Factors affecting interspecies variation in home-range size of raptors. Auk 117:511-517.

QGIS Development Team. 2016. QGIS Geographic Information System. Open Source Geospatial Foundation Project.

R Core Team. 2016. R: A language and environment for statistical computing. Vienna: $\mathrm{R}$ Foundation for Statistical Computing.

Rappole JH, Tipton AR. 1991. New harness design for attachment of radio transmitters to small passerines. Journal of Field Ornithology 62:335-337.

Schoener TW. 1968. Sizes of feeding territories among birds. Ecology 49:123-141.

Sealy SG. 1985. Erect posture of the young Black-billed Cuckoo: an adaptation for early mobility in a nomadic species. Auk 102:889-892.

Sechrist JD, Paxton EH, Ahlers DD, Doster RH, Ryan VM. 2012. One year of migration data for a western Yellow-billed Cuckoo. Western Birds 43:2-11.

U.S. Fish and Wildlife Service. 2008. Birds of Conservation Concern 2008. Arlington: U.S. Fish and Wildlife Service, Division of Migratory Bird Management.

Wiens JA. 2008. Habitat fragmentation: island v landscape perspectives on bird conservation. Ibis 137:S97-S104. 


\section{Figure 1 (on next page)}

Map of the study area.

Study area (red shaded box on the inset map) in southwest Florida, USA, where Mangrove Cuckoos (Coccyzus minor) were radio-tracked during 2012-2015. Individuals were captured in mangrove forest (green shading) within two protected areas: J.N. “Ding" Darling National Wildlife Refuge, located on the barrier island of Sanibel, and San Carlos Bay - Bunche Beach Preserve, located on the mainland in the city of Fort Myers. Individuals were tracked as far north as Port Charlotte, and as far south as Fort Myers Beach. 


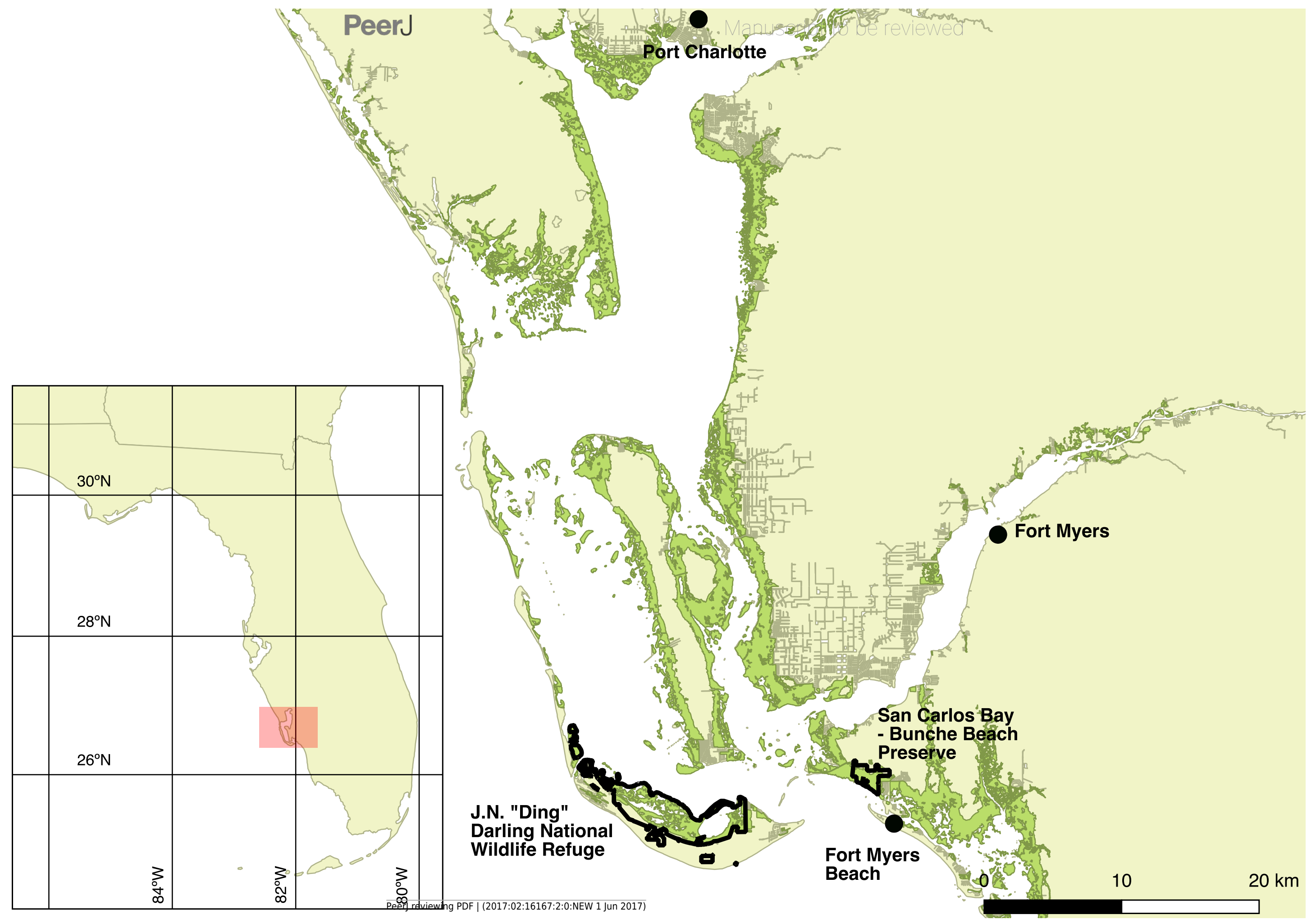


Figure 2 (on next page)

Seasonal distribution of captures of Mangrove Cuckoos.

Seasonal distribution of captures of Mangrove Cuckoos (Coccyzus minor) $(n=46)$ in southwest Florida during 2012-2015. 


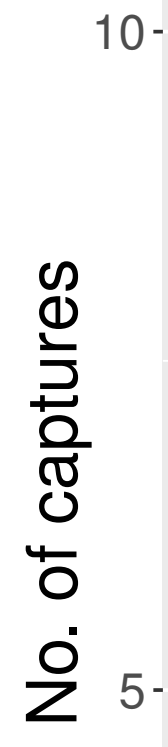

-
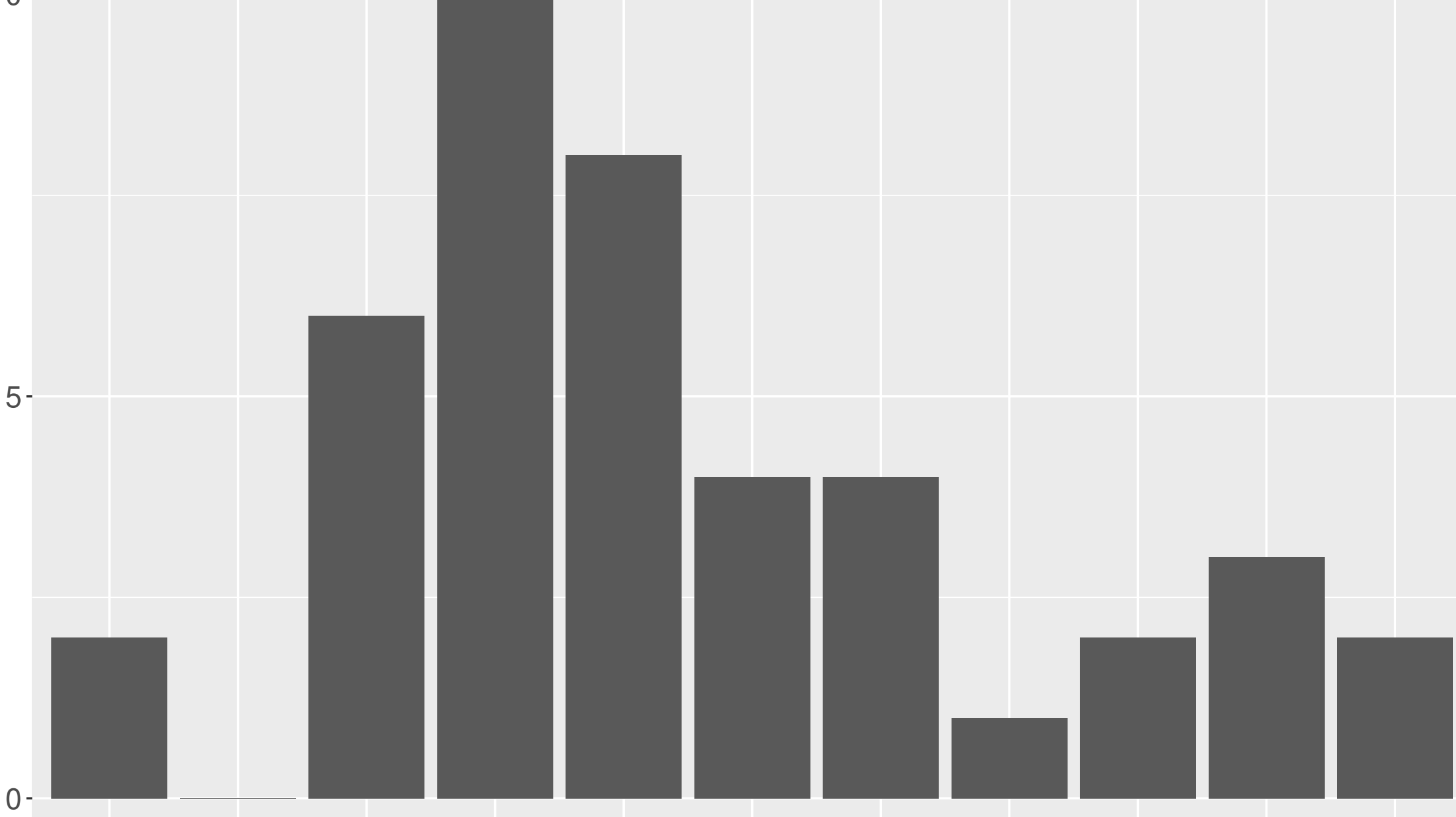

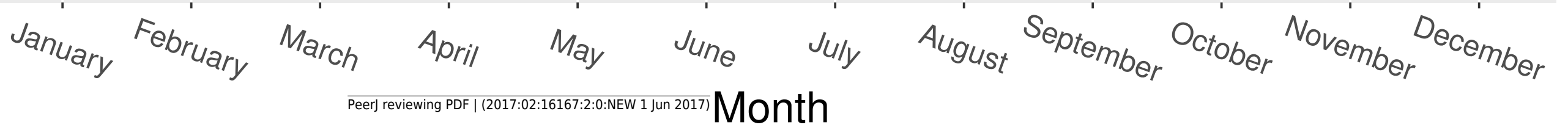


Figure 3 (on next page)

Daily movement distances of Mangrove Cuckoos.

Distance between estimated locations of individual radio-tagged Mangrove Cuckoos (Coccyzus minor) on subsequent days (i.e., estimated locations taken 18-28 hours apart) in southwest Florida from 2012-2015. Only individuals $(n=16)$ with an adequate number of relocations to estimate home-range boundaries are included. 


\section{Table $\mathbf{1}$ (on next page)}

Home-range characteristics of Mangrove Cuckoos.

Home-range characteristics of 16 Mangrove Cuckoos (Coccyzus minor) tracked via radiotelemetry on the southwest coast of Florida from 2012-2015. 
1 Table 1. Home-range characteristics of 16 Mangrove Cuckoos (Coccyzus minor) tracked via 2 radio-telemetry on the southwest coast of Florida from 2012-2015.

3

\begin{tabular}{|c|c|c|c|c|}
\hline \multirow[b]{2}{*}{ Individual } & \multirow[b]{2}{*}{$\mathrm{N}$} & \multicolumn{2}{|c|}{ Home-range area (ha) } & \multirow[b]{2}{*}{ Tracking dates } \\
\hline & & Core rea $^{\mathrm{a}}$ & Total $^{\mathrm{b}}$ & \\
\hline 148.811 & 57 & 42 & 153 & 3 Mar - 12 Jun 2014 \\
\hline 148.872 & 39 & 79 & 243 & 11 Mar - 27 May 2014 \\
\hline 149.281 & 20 & 91 & 243 & 4 Apr - 6 May 2014 \\
\hline 149.881 & 47 & 70 & 294 & 18 Apr - 27 Jun 2014 \\
\hline 149.990 & 26 & 9 & 28 & 25 Nov $2014-18$ Jan 2015 \\
\hline 150.612 & 37 & 24 & 92 & 28 Apr - 16 Jun 2012 \\
\hline 150.613 & 53 & 15 & 104 & 7 Jun - 22 Aug 2013 \\
\hline 150.621 & 42 & 30 & 107 & 8 May - 4 July 2012 \\
\hline 150.757 & 31 & 64 & NA & 9 May - 30 Jul 2013 \\
\hline 150.775 & 70 & 28 & 125 & 14 May - 22 Aug 2013 \\
\hline 150.819 & 42 & 60 & 201 & 18 Jun - 22 Aug 2013 \\
\hline 150.829 & 36 & 42 & 132 & $9 \mathrm{Jul}-22$ Aug 2013 \\
\hline 150.865 & 58 & 9 & 36 & 20 May - 22 Aug 2013 \\
\hline 150.874 & 76 & 76 & 319 & 15 Mar - 15 Jul 2013 \\
\hline 150.883 & 91 & 65 & 164 & 16 Mar - 22 Aug 2013 \\
\hline 150.919 & 20 & 24 & 86 & $8 \mathrm{Jul}$ - 10 Aug 2012 \\
\hline \multirow[t]{2}{*}{ MEAN } & & 45.5 & 155.1 & \\
\hline & & $(\mathrm{SD}=26.8)$ & $(\mathrm{SD}=88.3)$ & \\
\hline MEDIAN & & 42 & 132 & \\
\hline
\end{tabular}

$4 \quad$ a50\% isopleth from a Brownian bridges analysis.

5 b90\% isopleth from a Brownian bridges analysis. 